\title{
Ogólnopolska Konferencja Naukowa „Wincenty Lutosławski i literatura. Estetyczne koneksje - filozofia - recepcja", Białystok - Drozdowo, 11-12 października 2019 roku. Sprawozdanie
}

Pomysł zorganizowania konferencji naukowej poświęconej związkom z literaturą i kulturą XIX i XX wieku bodaj najwybitniejszego filozofa polskiego XIX stulecia, Wincentego Lutosławskiego (1863-1954), zrodził się w kręgu badaczy Młodej Polski z Uniwersytetu w Białymstoku. Prof. Jarosław Ławski zaproponował, by sesję na ten temat włączyć w cykl białostockich konferencji, których celem jest odczytanie zapoznanych wątków literatury modernistycznej: „Młoda Polska: rewizje, reinterpretacje”. III Ogólnopolska Konferencja z tego cyklu „Wincenty Lutosławski i literatura. Estetyczne koneksje - filozofia - recepcja" obradowała w Białymstoku i Drozdowie koło Łomży w dniach 11 i 12 października 2019 roku. Konferencję przygotowały wspólnie następujące instytucje:

- Katedra Badań Filologicznych „Wschód - Zachód”,

- Wydział Filologiczny Uniwersytetu w Białymstoku,

- Katedra Historii Literatury Pozytywizmu i Młodej Polski UJ,

* Jarosław Ławski - prof. dr hab., kierownik Katedry Badań Filologicznych „Wschód-Zachód” w Kolegium Litereturoznawstwa Uniwersytetu w Białymstoku. Autor monografii, m.in. Mickiewicz - Mit-Historia. Studia (Białystok 2010); Miłosz: „,Kroniki” istnienia. Sylwy (Białystok 2014).

1 Dwie poprzednie Konferencje z tego cyklu to: „Ironia modernistów”, Białystok 12-13 V 2017; „Tadeusz Miciński i ludzie epoki”, Białystok 11-12 X 2018 r. 
- Wydział Polonistyki Uniwersytetu Jagiellońskiego,

- Książnica Podlaska im. Łukasza Górnickiego w Białymstoku (Dział Naukowy),

- Muzeum Przyrody w Drozdowie.

Nad organizacją przedsięwzięcia jako imprezy cyklicznej czuwał Komitet Naukowy, złożony z przedstawicieli współorganizatorów całego cyklu „Młoda Polska: rewizje, reinterpretacje", to jest profesorów Uniwersytetu Jagiellońskiego i Uniwersytetu w Białymstoku². Z kolei prace nad sesją o Lutosławskim wziął na swe barki Komitet Organizacyjny, któremu przewodniczyli: dr Marcin Bajko z Katedry Badań Filologicznych „Wschód - Zachód” UwB, dr Urszula M. Pilch z Katedry Historii Literatury Pozytywizmu i Młodej Polski UJ oraz Pani dyr. Anna Archacka z Muzeum Przyrody w Drozdowie ${ }^{3}$. Konferencja zgromadziła 21 badaczy z Polski, Hiszpanii, Niemiec, Ukrainy i Austrii, którzy podjęli następujące tematy:

- Wincenty Lutosławski jako pisarz, publicysta.

- Literatura w filozoficznym dziele Lutosławskiego, filozofia w jego eseistyce i publicystyce.

- Biograficzne meandry filozofa.

- Myśl filozoficzna Lutosławskiego na tle XIX i XX wieku.

- Autokreacje Lutosławskiego.

- Środowisko domowe i świat w życiu i dziele filozofa.

2 W skład owego Komitetu Naukowego wchodzą: prof. Anna Czabanowska-Wróbel - Katedra Historii Literatury Pozytywizmu i Młodej Polski UJ, dr hab. Anna Janicka, prof. UwB - Wydział Filologiczny UwB, prof. dr hab. Dariusz Kulesza - Katedra Literatury Międzywojennej i Współczesnej UwB, prof. Jarosław Ławski - Katedra Badań Filologicznych „Wschód - Zachód” UwB, prof. Gabriela Matuszek-Stec - Katedra Historii Literatury Pozytywizmu i Młodej Polski UJ, prof. Ryszard Nycz - Katedra Antropologii Literatury i Badań Kulturowych, Wydział Polonistyki UJ, prof. Magdalena Popiel - Katedra Antropologii Literatury i Badań Kulturowych, Wydział Polonistyki UJ, prof. Marian Stala - Katedra Historii Literatury Pozytywizmu i Młodej Polski UJ, dr hab. Piotr Stasiewicz - Wydział Filologiczny UwB, dr hab. Anna Wydrycka, prof. UwB - Wydział Filologiczny UwB.

3 W skład Komitetu Organizacyjnego weszli także: dr Łukasz Zabielski - Książnica Podlaska im. Łukasza Górnickiego (Dział Naukowy), dr Michał Siedlecki - Książnica Podlaska im. Łukasza Górnickiego (Dział Naukowy), mgr Danuta Niebrzydowska - Wydział Filologiczny UwB, dr Kamil K. Pilichiewicz - Uniwersytet w Białymstoku, Książnica Podlaska, mgr Natalia Szabołtas - Zakład Filologicznych Badań Interdyscyplinarnych UwB, mgr Patryk Suchodolski - Książnica Podlaska im. Łukasza Górnickiego. 


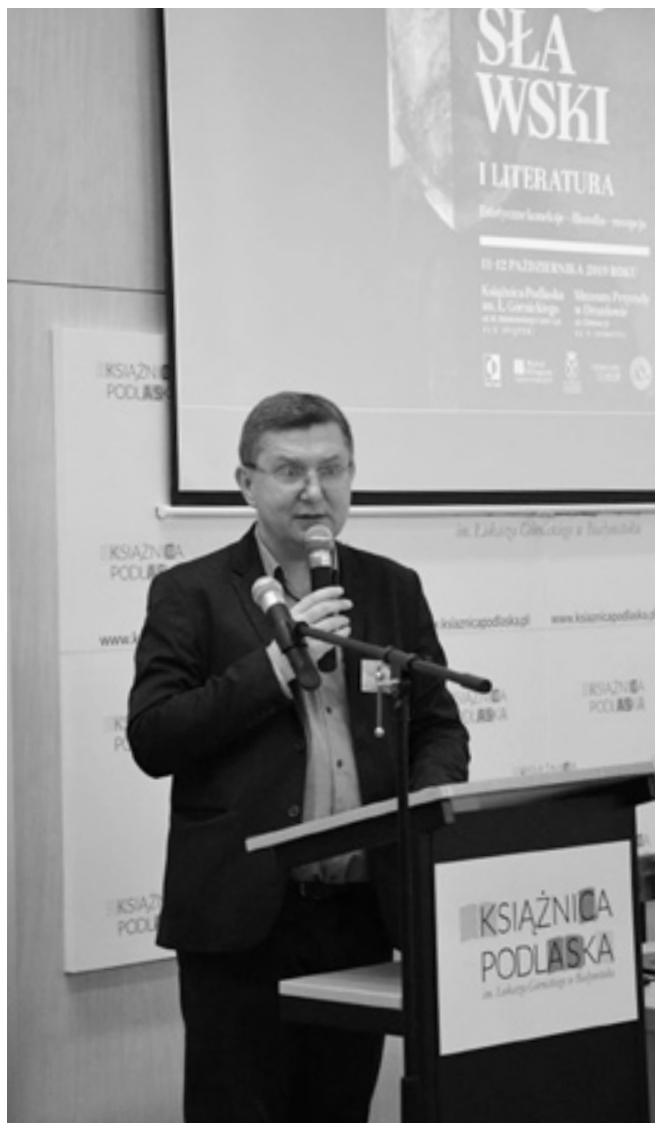

Otwarcie Konferencji. Na zdjęciu prof. Jarosław Ławski (UwB, Białystok).

Fot. Bogumiła Maleszewska-Oksztol (Książnica Podlaska)

- Elentua, Eleusis, Towarzystwo Kowali.

- Lutosławski wobec XIX- i XX-wiecznej nowoczesności.

- Miejsce kobiety i mężczyzny w imaginarium i myśli Lutosławskiego.

- Lutosławski i sławni ludzie XIX i XX wieku.

- Recepcja dzieła filozofa z Drozdowa4.

Gości Konferencji powitali 11 X (piątek) w Sali Audytoryjnej Książnicy Podlaskiej im. Łukasza Górnickiego Pani Jolanta Gadek, Dyrektor tej placów-

4 Cyt. za: Program Konferencji, opr. D. Kukiełko, M. Bajko, U. M. Pilch, opr. graf. H. Pilcicki, Białystok-Drozdowo 2019, s. 4. 


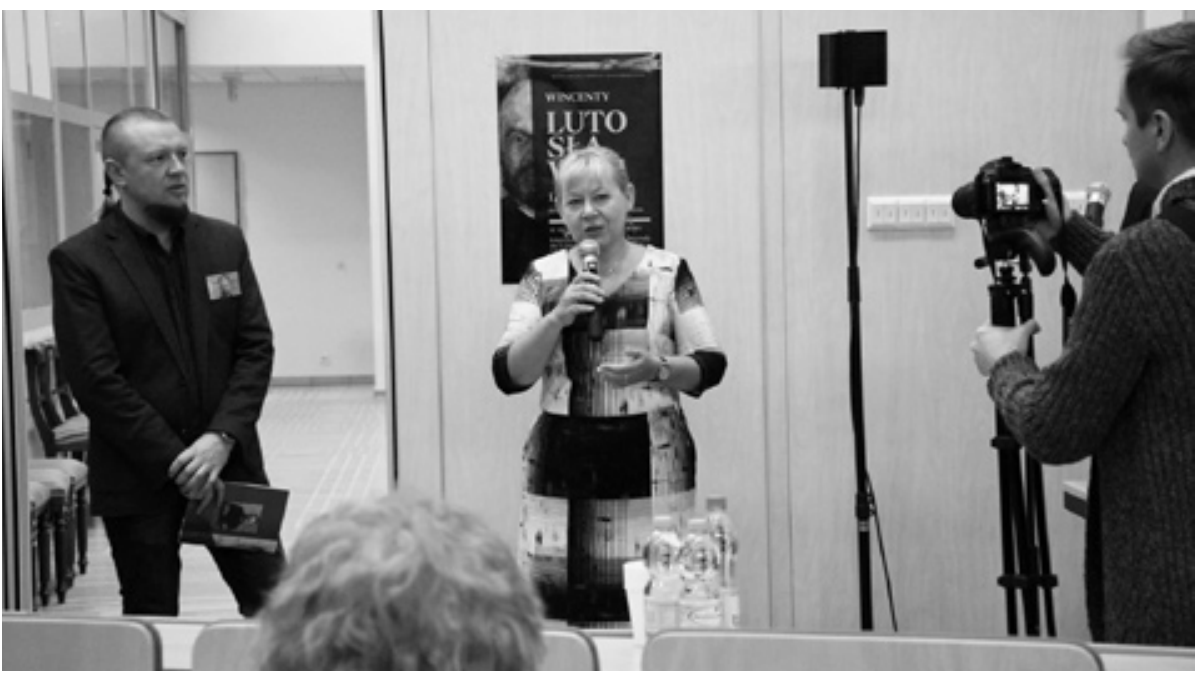

Otwarcie Konferencji. Na zdjęciu od lewej: dr Marcin Bajko (UwB, Białystok), dyr. Jolanta Gadek (KP, Białystok).

Fot. Bogumiła Maleszewska-Oksztol (Książnica Podlaska)

ki, a także prof. Jarosław Ławski, dziekan Wydziału Filologicznego UwB. Następnie o celach sesji zwięźle mówili dr Urszula M. Pilch (UJ) i dr Marcin Bajko (UwB). Uroczystego otwarcia Konferencji dokonała znakomita badaczka literatury Młodej Polski, edytorka dzieł Stanisława Przybyszewskiego, prof. Gabriela Matuszek-Stec z Uniwersytetu Jagiellońskiego.

Obrady trwające od godz. 9.00 aż do 18.30 miały charakter żywej, elitarnej, specjalistycznej dyskusji przedstawicieli różnych dyscyplin humanistycznych: filologów, filozofów i historyków. Dyskusje prowadzili: prof. Gabriela Matuszek-Stec (UJ), dr Marcin Bajko (UwB), dr hab. Hanna Ratuszna, prof. UMK (Toruń), dr hab. Elżbieta Flis-Czerniak, prof. UMCS (Lublin), dr hab. Jan Stanisław Ciechanowski (UW). Wymieńmy tematy kilku tylko z ponad dwudziestu referatów:

- dr hab. Hanna Ratuszna, prof. UMK (Toruń), Wincenty Lutosławski pesymizm i pesymiści;

- dr hab. Elżbieta Flis-Czerniak (UMCS, Lublin), ,,Zaraza” pozytywizmu. Dialog Wincentego Lutosławskiego z Bolesławem Prusem;

- prof. dr hab. Zbigniew Chojnowski (UWM, Olsztyn), Poezja w refleksji Wincentego Lutosławskiego; 
- mgr Irena Szewczenko (UwB, Białystok), Lutosławski w Europie Wschodniej: Rosja, Ukraina;

- dr Marlis Lami (Kraków/Wiedeń), Guru i Mesjasz Wincenty Lutosławski. Rozwój potęgi woli przez psychofizyczne ćwiczenia, 1909;

- mgr Jerzy Ziemacki (UW, Warszawa), Droga myśli Wincentego Lutostawskiego a ,odkrycie jaźni”;

- dr hab. Anna Janicka, prof. UwB (Białystok), Lutosławski o kobiecie;

- dr Damian Makuch (UW, Warszawa), Estetyka i etyka Lutosławskiego na tle odrodzenia polskiego idealizmu przełomu wieków;

- dr hab. Cristina González Caizán (Laboratorium Sofía Casanova, Wydział „Artes Liberales” UW), Nieznana korespondencja z lat 1896-1913 pomiędzy Wincentym Lutosławskim oraz hiszpańskim filozofem, pedagogiem i eseista Francisco Ginerem de los Rios, twórca Wolnego Instytutu Nauczania (Institucion Libre de Ensenanza).

Obrady piątkowe zakończyła długo celebrowana kolacja w Restauracji „Kawelin” (ul. Legionowa 10).

Kolejny dzień Konferencji miał charakter sesji wyjazdowej do Muzeum Przyrody w Drozdowie, instytucji pielęgnującej pamięć o rodzie Lutosławskich. Muzeum to już wkrótce zmieni chroniącą to dziedzictwo w czasach PRL-u nazwę na inną: Dwór Lutosławskich. Należy podkreślić gościnność, z jaką Dyrekcja i pracownicy Muzeum Przyrody przyjęli badaczy. Atmosfera, w jakiej odbywała się drozdowska część obrad, była serdeczna, niemal rodzinna. Gości przybyłych autobusem z Białegostoku oprowadzono najpierw po ogrodzie przylegającym do dworu. Uczestników powitała w progach placówki Pani Dyrektor Anna Archacka. Badacze zwiedzili dwór, ekspozycję, obejrzeli między innymi przewoźne biurko-walizkę Lutosławskiego, które udostępnili pracownicy Muzeum. Następnie zaczęła się część naukowa obrad. Miała ona trzyczęściowy charakter: wysłuchano wystąpienia dra Michała Siedleckiego z Książnicy Podlaskiej, które nie zmieściło się w programie obrad prowadzonych poprzedniego dnia w Białymstoku (,,Metafizyka” - wokót głównych zagadnień systemu filozoficznego Wincentego Lutosławskiego).

Po krótkiej przerwie odbyło się poprowadzone przez prof. Annę Janicką spotkanie ze specjalnym Gościem Konferencji, dr Hanną Liberą, prawnuczką Wincentego Lutosławskiego. Dr Libera jest z wykształcenia magistrem polonistyki (absolwentka UAM w Poznaniu) oraz niemieckim doktorem 


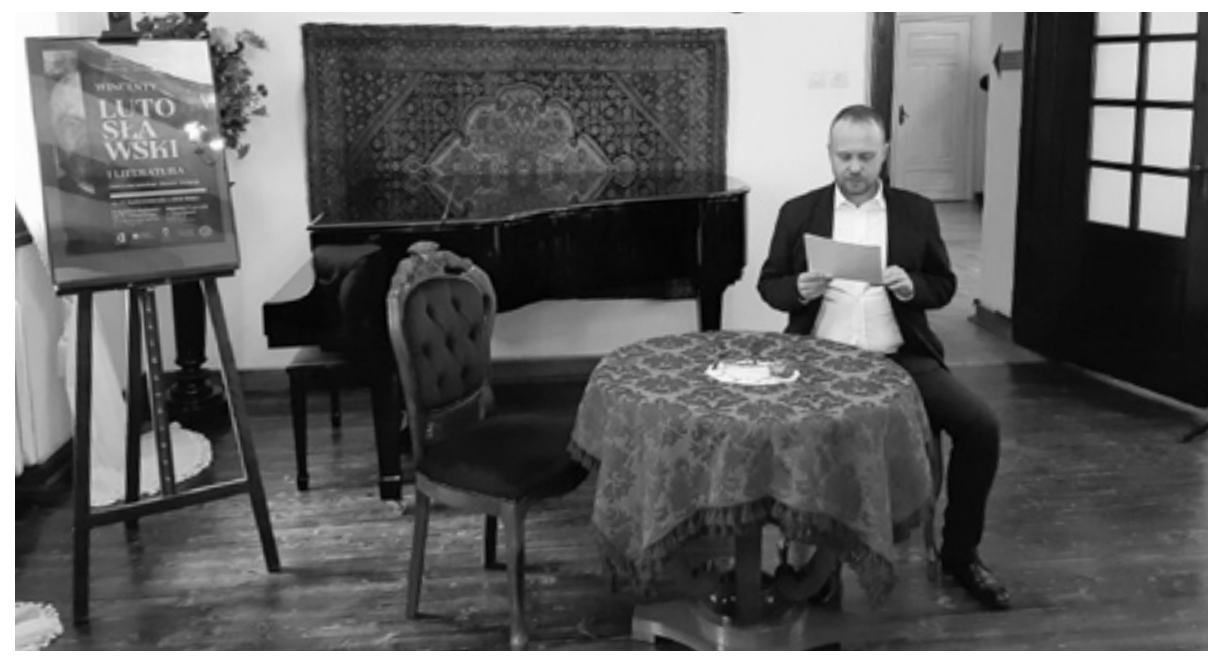

Drozdowo. Drugi dzień Konferencji.

Na zdjęciu dr Michał Siedlecki (Książnica Podlaska)

nauk medycznych, cenionym ginekologiem, chirurgiem pracującym w Essen w Niemczech ${ }^{5}$. Jak podkreślała, w rodzinie bardzo żywa jest pamięć nie tylko Wincentego Lutosławskiego, lecz również jego żony, hiszpańskiej pisarki Sofii Guadalupe Pérez Casanova (1861-1958), która przez małżeństwo z filozofem na całe życie związała się z Polską. Spotkanie miało charakter bardzo ciekawej, żywej rozmowy, w czasie której poruszono chociażby takie tematy, jak: droga życiowa dr Libery od polonistki do lekarza, twórczość jej męża, prof. Leszka Libery, autora głośnego Utopka6, związki rodu Lutosławskich z Hiszpanią od XIX do XXI wieku, stosunek różnych przedstawicieli rodziny do tradycji myśli endeckiej, Romana Dmowskiego (rozejście się z nim dróg Lutosławskiego), miejsce religii, muzyki, obyczaju w życiu Lutosławskich. Rozmowa z dr Liberą znajdzie się w publikacji pokonferencyjnej.

5 Jej rozprawa doktorska została wydana w Poznaniu: H. Z. Libera, Bestimmung von Normwerten von Uterus und Ovarien in der Magnetrezonanztomographie in Abhängigkeit von Alter und Zyklusphase gesunder Probandinnnen, Poznań 2007.

6 Utopek to pierwsza część trylogii napisanej przez Leszka Liberę po niemiecku. Dotychczas ukazały się po polsku dwie części: Utopek, przeł. S. Lisiecka, Łódź 2018; Buks Molenda. Powieść, przeł. S. Lisiecka, Łódź 2019. 
Po rozmowie przystąpiono do ostatniej naukowej części spotkania. Obrady poprowadził prof. Zbigniew Chojnowski (UWM, Olsztyn). Referaty wygłosili:

- Adiunkt Tomasz Szymański (Muzeum Przyrody w Drozdowie), Lutosławscy. Zarys historii rodu ziemian, twórców kultury i ludzi idei;

- dr hab. Jan Stanisław Ciechanowski (Laboratorium Sofía Casanova, Wydział „Artes Liberales” UW), Hiszpański kontekst życia i tworczości Wincentego Lutosławskiego;

- Kustosz Marcin Rydzewski (Muzeum Przyrody w Drozdowie), Spuścizna materialna po Wincentym Lutosławskim w Drozdowie - inspiracja do miejscowych badań.

Konferencję zamknęły wystąpienia byłej Dyrektor Muzeum w Drozdowie Pani Stanisławy Chyl, dyr. Anny Archackiej i prof. Jarosława Ławskiego 7 . Ten ostatni zapowiedział wydanie w 2020 roku monografii pokonferencyjnej, a także zaproponował zorganizowanie w 2021 roku kolejnej, tym razem międzynarodowej konferencji poświęconej Wincentemu Lutosławskiemu i Sofii Casanovie, którą wsparłby Wydział Filologiczny Uniwersytetu w Białymstoku. Zgodnie uznano białostocko-drozdowskie spotkanie za bardzo udane.

Organizatorzy Konferencji zostali obdarowani przez Muzeum Przyrody najnowszą publikacją tej placówki, tomem Danuty i Aleksandra Wroniszewskich Koniec świata Lutosławskich ${ }^{8}$. Odnieśliśmy wszelako w czasie tych dwu dni wrażenie, iż ów „koniec” należy rozumieć li tylko w historycznym wymiarze, albowiem tradycja Wincentego Lutosławskiego i Sofii Casanovy okazała się wciąż żywa i pasjonująca.

$7 \quad$ Warto podkreślić, iż za sprawą mgra Dominika Sołowieja informacja o konferencji znalazła się na licznych forach internetowych, m.in.:

- https://www. facebook.com/klubczytelniczyExLibris/?modal=admin_todo_tour;

- https://goingapp.pl/evt/2164557/wincenty-lutoslawski-i-literatura-konferencja-naukowa;

- https://wzasiegu.pl/wydarzenie/wincenty-lutoslawski-i-literatura/?instance_id=13;

- https://www.facebook.com/612970572236202/photos/a.613467615519831/123908440 9624812/?type $=3 \&$ theater;

- https://dominiksolowiej.pl/2019/10.07/wincenty-lutoslawski-i-literatura-iii-ogolnopolskakonferencja-naukowa;

- http://unikonferencje.pl/konferencja/10912-wincenty-lutoslawski-i-literatura.

8 D. i A. Wroniszewscy, Koniec świata Lutosławskich, Drozdowo 2019, ss. 348. Wydawcą tomu jest Fundacja Sztuk i Dialogu, partnerem Muzeum Przyrody - Dwór Lutosławskich w Drozdowie, a współfinansowali edycję: Starostwo Powiatowe w Łomży, Urząd Miejski w Łomży i Fundusz Inicjatyw Obywatelskich. Druk: Libra-Print w Łomży. 